\title{
Argentina frente al gobierno de Allende, la mirada del diario Río Negro
}

\section{Argentina against the Allende government, the look of daily Río Negro}

Alfredo Azcoitia $\mathrm{a}^{*}(\mathbb{D}$ (http://orcid.org/0000-0002-1398-7655)
Recibido el 26 de septiembre de 2016.

Aceptado el 27 de enero de 2017.

*Autor para correspondencia: Alfredo Azcoitia, correo electrónico: alfazkoitia@hotmail.com

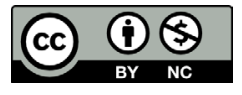

Todos los contenidos de Estudios Fronterizos se publican bajo la licencia Creative Commons Atribución no comercial 2.5 México, y pueden ser usados gratuitamente para fines no comerciales, dando el crédito a los autores y a la revista Estudios Fronterizos. a Universidad Nacional de Río Negro, San Carlos de Bariloche, Argentina, correo electrónico: alfazkoitia@hotmail.com

\section{Resumen}

En el presente artículo abordamos las noticias sobre los vínculos argentino-chilenos que circularon por el diario más influyente de la Norpatagonia argentina durante el gobierno de Salvador Allende (1970-1973). A través de herramientas del análisis del discurso damos cuenta de las múltiples dimensiones que condicionaron dichos discursos como también de los sentidos que adquirieron las relaciones binacionales en el marco de los mismos. Consideramos que este tipo de estudios contribuyen a deconstruir las miradas esencializadas sobre el otro, dando cuenta de las diversas aristas contenidas en las representaciones que circulan a través de la prensa. Esto adquiere mayor relevancia en el caso de la Norpatagonia, al tratarse de una región cuyos vínculos con Chile configuran una experiencia tan histórica como cotidiana. En este sentido, los discursos que prevalecieron en el Río Negro construyeron un Chile cuyo pasado y presente lo vinculaba íntimamente al futuro de la Argentina y la región.

Palabras clave: prensa, relaciones binacionales, ideología, discursos.

\section{Abstract}

In the present article we address the news about the Argentine-Chilean ties that circulated through the most influential newspaper of Argentine Norpatagonia during the years of the government of Salvador Allende (1970-1973). Through the tools of discourse analysis we realize the multiple dimensions that conditioned the discourses as well as the meanings acquired by binational relations within the framework of the discourses. We consider that this type of studies contributes to deconstruct the essential glances over the other, giving account of the several edges contained in the representations that circulate through the press. This acquires greater relevance in the case of the Northern Patagonia, it is in a region whose links with Chile set up an as historical as everyday experience In this sense, the discourses that prevailed in the Río Negro built a Chile Its past and present intimately linked it to the future of Argentina and the region. 
Keywords: press, binational relations, ideology, discourses.

\section{Introducción}

En 1958, el triunfo de la Revolución Cubana marcó el comienzo de una época en América Latina caracterizada por una notable politización y por la percepción creciente sobre la inminencia del cambio social (Gilman, 2003). En este contexto, se sucedieron en Chile una serie de gobiernos, apoyados financiera y políticamente por los Estados Unidos, que asumieron un proyecto reformista tendiente a realizar la modernización capitalista e impulsar la participación de los sectores populares, como forma de contener el constante crecimiento de las fuerzas de izquierda (Moulián, 2006). A pesar de ello, en las elecciones presidenciales de 1970 el candidato de la Unidad Popular, Salvador Allende, obtuvo un histórico triunfo dando comienzo a una experiencia "insólita", como la calificara Fidel Castro, tendiente a generar condiciones para la transformación radical del orden social y económico a través de la "democracia burguesa”.

Este escenario inédito que se abría en Chile hacía presumir que las relaciones con la Argentina ingresarían en una etapa signada por la tensión, habido en cuenta el enérgico antimarxismo que públicamente declamaba la dictadura militar de ese país. Enmarcado en la Doctrina de Seguridad Nacional, ${ }^{1}$ el gobierno de facto del general (R) ${ }^{2}$ Juan Carlos Onganía (1966-1970) compartía con sus camaradas de arma brasileños tanto la tesis sobre la existencia de "fronteras ideológicas" como la necesidad de conformar una alianza militar supranacional para custodiarlas (Rapoport, 2005; Zapata y Zurita, 2005). En este marco, el triunfo de la Unidad Popular amenazaba con profundizar las contradicciones ideológicas entre los gobiernos de ambos países, convirtiendo a la Cordillera en una nueva "cortina de hierro".

En función de este nuevo escenario abierto en 1970, en el presente artículo nos proponemos analizar la postura en torno a las relaciones binacionales adoptada por el diario Río Negro durante los años de gobierno de la Unidad Popular. Consideramos que centrar la investigación en este medio, de cuya relevancia daremos cuenta en el apartado siguiente, nos permite interpretar los múltiples sentidos sobre los vínculos argentino-chilenos que ejercieron mayor influencia en la opinión pública norpatagónica. Asimismo, cabe señalar que en las páginas de este diario no solo se expresaron los intereses políticos y económicos de una empresa periodística, sino también las condiciones de producción y circulación de un discurso polifónico atravesado por las particularidades propias de una región fronteriza. En el caso de la Norpatagonia, estamos refiriendo a una región cuya configuración territorial estuvo históricamente tensionada entre los estrechos vínculos transcordilleranos, forjados al calor de los tempranos intercambios comerciales

\footnotetext{
1 Durante los años de la Guerra Fría, la Doctrina de Seguridad Nacional se estructuró en función del enfrentamiento entre el "comunismo internacional apátrida" y el "mundo occidental y cristiano". En el marco de este conflicto que se desarrollaba más allá de las fronteras estatales, las Fuerzas Armadas transformaron a la nación en "teatro de operaciones" desplegando su potencial represivo sobre el "enemigo interior", un otro ideológico que al "mimetizarse" con el resto de la población, debía ser identificado, excluido y posteriormente eliminado. En la Argentina, esta doctrina adquirió características propias al entrelazar la lucha contra el comunismo con la preocupación por contener el avance del peronismo (Ansaldi, 2004; Mazzei, 2012).

${ }^{2}(\mathrm{R})$ retirado de la fuerza a la que pertenecía.
} 
y de la permanente afluencia de migrantes chilenos así como el sempiterno temor a la "permeabilidad" de una región fronteriza "débilmente argentinizada", que se cristalizó en hipótesis de conflicto alimentadas por las más diversas teorías conspirativas propaladas por los sectores nacionalistas (Bohoslavsky, 2009). De esta manera, resulta sugestivo analizar uno de los discursos sobre las relaciones binacionales que mayor influencia ejerció en este particular escenario, en momentos que Chile parecía encaminarse hacia el socialismo. En este sentido, sostenemos como hipótesis inicial que en el contexto que acabamos de describir, el diario rionegrino mantuvo la línea editorial predominante en los años anteriores, tendiente a presentar la integración como un objetivo permanente frente al cual debían subordinarse cualquier otra diferencia circunstancial.

En este sentido, resulta importante recordar que las empresas periodísticas se presentan ante sus lectores como meros transmisores de una "realidad" que "reflejan objetivamente" en sus páginas a través de un lenguaje en apariencia transparente que les permite sostener su pretendida neutralidad (Wodak y Meyer, 2003). Este discurso logra legitimarse a través de la acción de la propia prensa, la cual apela al sistema informativo como fuente principal de su construcción, a la vez que otorga cierta homogeneidad en los acontecimientos publicados que afianza el tipo de realidad que describen (Rodrigo, 2005). Esta capacidad de establecer y extender dicha ficción les permite acrecentar su influencia sobre la opinión pública y así consolidar su lugar de actor político en condiciones de afectar el proceso de toma de decisiones en el sistema político (Borrat, 1989, p. 10). De esta manera, analizar el discurso periodístico nos lleva a adentrarnos en la trama de sentido que se inserta, teniendo siempre presente que los propietarios de los medios tienen intereses y poseen una concepción del mundo, de modo que, de todos los hechos, seleccionarán principalmente aquellos que consideren apropiados para informar y construir sus mensajes (Raiter y Zullo, 2008).

El análisis propuesto en el artículo procura contribuir a la rica producción historiográfica sobre las relaciones argentino-chilenas que ha venido desarrollándose en los últimos años. Luego del claro predominio que hubo en la década de los años sesenta y setenta de trabajos centrados en el conflicto territorial, el retorno de la democracia propició una constante ampliación temática sobre los estudios binacionales. En este sentido, la Norpatagonia ha aportado una abundante y completa producción científica en torno a las particulares relaciones y dinámicas establecidas en esta región fronteriza. Precisamente es en esta línea en la que se enmarca nuestro artículo, adoptando una perspectiva centrada en la construcción del otro, la cual reconoce como antecedentes los trabajos de Pablo Lacoste (2003) y Ernesto Bohoslavsky (2009).

El artículo comienza con un breve recorrido por la línea editorial sostenida por el diario en torno a las relaciones entre Chile y Argentina hasta 1970. Posteriormente analizamos la postura del diario Río Negro ante el triunfo de Salvador Allende, pasando luego a abordar la perspectiva que adoptó frente al "pluralismo ideológico" impulsado por la política exterior del dictador Agustín Alejandro Lanusse (1971-1973). Recorreremos también los cambios que se evidenciaron en la superficie redaccional del diario después de los incidentes diplomáticos generados en 1972 tras los hechos de Rawson y Trelew, para finalizar analizando la posición asumida por el diario frente al golpe de Estado en Chile. 


\section{La lectura del Río Negro sobre las relaciones argentino-chilenas (1960-1970)}

Desde su primera aparición por las calles rionegrinas de la ciudad de General Roca, al norte de la Patagonia, el periódico fundado en 1912 por Fernando Emilio Rajneri explicitó con claridad su intención de convertirse en una voz influyente en la opinión pública regional (Ruffini, 2001). Bajo la dirección de Fernando Emilio Rajneri hijo (1960-1967) y luego de Julio Raúl Rajneri (1967-1986) el Río Negro, convertido en diario desde 1958, alcanzó el liderazgo regional en la década de los sesenta, transformándose durante las siguientes décadas (setenta y ochenta) en una de las empresas periodísticas más importantes del país. Esta relevancia alcanzada por el diario tiene su explicación en una multiplicidad de causas, una de las cuales fue sin duda los estrechos vínculos que la familia propietaria del Río Negro supo establecer con distintos gobiernos, tanto provinciales como nacionales. También debemos señalar la permanente inversión en equipamiento que no solo le permitió incrementar su publicación sino también modernizar su estética haciéndolo más atractivo para el lector. Al prestigio, la permanente innovación tecnológica y sus vínculos empresariales y políticos, se suma las dificultades de sus competidores regionales para sostener la circulación de sus publicaciones. Todos estos elementos convierten al Río Negro en una referencia ineludible a la hora de indagar sobre las representaciones que impactaron de manera más significativa en la opinión pública norpatagónica en torno a las relaciones entre la Argentina y Chile.

En este sentido, a comienzos de 1960, el diario apoyaba iniciativas como la creación de la Asociación Latinoamericana de Libre Comercio, ${ }^{3}$ tendientes a impulsar la integración regional. Desde la perspectiva del Río Negro estos procesos eran imprescindibles tanto para alcanzar el desarrollo económico como para garantizar la estabilidad institucional en América Latina. En este escenario, Chile emergía de las páginas del diario como un ejemplo a seguir, contando con una clase política consustanciada con el espíritu "americanista” que le permitía supeditar las querellas domésticas y los diferendos territoriales al imperativo histórico de la integración (Azcoitia, 2016). Si bien este clima favorable al acercamiento entre ambos países se profundizó durante las presidencias del argentino Arturo Illia (1963-1966) y el chileno Eduardo Frei (19641970), ${ }^{4}$ el conflicto suscitado por el incidente de "Laguna del Desierto" evidenció que tanto la cuestión territorial, como el temor al eterno "enemigo expansionista", no

\footnotetext{
${ }^{3}$ Esta asociación nacida en febrero de 1960, inicialmente estuvo conformada por los gobiernos de Argentina, Chile, Brasil, Uruguay, México, Paraguay y Perú. En 1961 también lo suscribieron Colombia y Ecuador. Cinco y seis años después lo ratificaron Venezuela y Bolivia respectivamente. El objetivo de estos acuerdos era la progresiva eliminación de aranceles en vista a la creación de zona de libre comercio.

${ }^{4}$ Ambos gobiernos no solo compartían un marcado sentido latinoamericanista, sino también la convicción de que la integración les permitiría disminuir en la región tanto la injerencia de Washington como la creciente influencia de la dictadura brasileña (Cisneros y Escudé, 2000; Medina, 2002; Simonoff, 2007).

${ }^{5}$ Este hecho ocurrido en la zona fronteriza denominada "Laguna del Desierto" desató un serio conflicto diplomático que se profundizó con el posterior enfrentamiento entre gendarmes y carabineros, que arrojó como saldo la muerte de un oficial chileno. A pesar del clima de fraterno y cordialidad que había imperado en el marco de la entrevista entre Illia y Frei, desarrollada en la ciudad de Mendoza apenas unos pocos días antes, los sectores nacionalistas lanzaron en la argentina una campaña, a la que se plegó una parte significativa de la prensa, azuzando a la opinión pública sobre las cuestiones fronterizas pendientes (Cisneros y Escudé, 2000; Mazzei, 2012; Valenzuela, 1999).
} 
solo conservaban su vigencia en el universo castrense sino también su capacidad de influir en la opinión pública. En este escenario, la línea editorial del Río Negro apeló a los "seculares lazos de amistad", al "origen común" y al aporte fundamental de los trabajadores chilenos para la economía norpatagónica, reinstalando así, en un contexto dominado por el nacionalismo territorial, la idea de la unidad como imperativo histórico que debía guiar a las relaciones binacionales (Azcoitia, 2016).

Tras el golpe de junio de 1966, la dictadura argentina comenzó un acercamiento hacia su par brasileña, con la cual compartían tanto el alineamiento con los Estados Unidos, como la posibilidad de conformar una alianza militar sobre la base de la existencia de "fronteras ideológicas" (Rapoport, 2005; Zapata y Zurita, 2005). En este contexto, el presidente Eduardo Frei comprendió que debía aliarse con los gobiernos democráticos que subsistían en la región para evitar aislamiento político en el Cono Sur (Medina, 2004; Valenzuela, 1999). El distanciamiento entre ambos países se plasmó tempranamente en la superficie redaccional del Río Negro a través de la proliferación de noticias que daban cuenta del desplazamiento de la integración por el de los conflictos limítrofes como tema destacado de la agenda binacional (Azcoitia, 2016).

A pesar del discurso nacionalista territorial que predominó durante la presidencia de facto de Juan Carlos Onganía (1966-1970), del cual la línea editorial del diario no estuvo completamente ajena, a fines de los sesenta comenzó a evidenciarse un cambio en materia de política exterior que implicó el reemplazo de la tesis de "fronteras ideológicas" por la del "pluralismo ideológico". A fines de 1968 habían comenzado a producirse una serie de conflictos que revelaron la creciente combatividad y politización del movimiento obrero y estudiantil, erosionando la figura de Onganía como garante del orden público (Pozzi y Schneider, 2000). Paralelamente, el panorama internacional también se presentaba adverso debido al distanciamiento con la dictadura brasileña y las tensiones con la Casa Blanca. ${ }^{6}$ En este complejo escenario, la cancillería argentina comenzó un tenue acercamiento hacia Chile tendiente a encontrar un socio que lo apoyara en sus negociaciones con los EE. UU. y a la vez permitiera equilibrar el poder creciente que Brasil estaba adquiriendo en la región. Este nuevo contexto se evidenció en las páginas del Río Negro a través del repliegue de los temas vinculados a los diferendos limítrofes junto con el retorno del integracionismo como estructurante de la agenda binacional. ${ }^{7}$ Sin embargo, a medida que crecía la posibilidad de que más allá de la cordillera triunfara un candidato presidencial que públicamente se asumía como marxista, el futuro de las relaciones entre ambos países se tornaba cada vez más incierto.

\section{Triunfo de la Unidad Popular y "pluralismo ideológico"}

Durante las elecciones chilenas, las noticias publicadas por el diario Río Negro enfatizaban el "crecimiento de la violencia" junto con la "euforia política" como rasgos

\footnotetext{
${ }^{6}$ La estrategia norteamericana de convertir a los ejércitos de la región en fuerzas eficaces para la lucha antiguerrillera pero desprovistas de material avanzado para la guerra convencional, se contraponía con el objetivo de las Fuerzas Armadas argentinas de adquirir equipamiento bélico (Rapoport, 2005).

${ }^{7}$ Cf. "La reunión de Onganía y Frei", 10 de enero de 1970.
} 
salientes de un comicio que caracterizaba como un "plebiscito doctrinario". ${ }^{8}$ En este sentido, el cronista enviado a cubrir el tema manifestaba su sorpresa por la "polarización en torno a los conceptos de derecha e izquierda", a la vez que destacaba la masiva participación popular. En sus notas daba cuenta también de las versiones que circulaban en Chile en caso de triunfar la Unidad Popular, las cuales iban desde un golpe de Estado hasta una posible intervención de los militares argentinos. ${ }^{9}$ Las noticias sobre familias acaudaladas adquiriendo pasajes para huir hacia Argentina o Estados Unidos, junto con las referidas al contrabando de armas por los pasos patagónicos para los "grandes propietarios" chilenos que buscaban defender sus fundos, terminaban de configurar un escenario de fractura social que amenazaba con sumir a Chile en una crisis política sin precedentes. ${ }^{10}$ Sin embargo, las noticias sobre el resultado electoral daban cuenta del "júbilo" popular manifestado en los improvisados "carnavales" callejeros ante el triunfo de un gobierno "antiimperialista, patriótico y nacional", como lo caracterizaban los principales referentes de la Unidad Popular. ${ }^{11}$ Cabe destacar que en su espacio editorial el Río Negro asumió una posición expectante frente a lo que definía como la "más inquietante experiencia latinoamericana del momento" advirtiendo sobre el dilema que enfrentaba la "democracia en el sentido tradicional", la cual se encontraba tensionada entre la reacción y "los cambios revolucionarios". ${ }^{12}$

En la sección "Actualidad internacional", el diario sostenía que el proceso chileno era una demostración que la izquierda era "cruenta" cuando se la "obligaba" En este sentido, condenó el asesinato del general Schneider afirmando que hechos de esta naturaleza consolidaban "la efervescencia revolucionaria latinoamericana" justificando el recurso de la violencia. ${ }^{13}$ La posición asumida por Río Negro respecto a la situación chilena tenía su correlato con la demanda a la dictadura argentina por una salida electoral sin proscripciones, la cual entendía como la forma de resolver la conflictividad política a través de la vía institucional, en el contexto de un sostenido crecimiento del accionar guerrillero.

Por su parte, las noticias sobre las repercusiones en la Argentina configuraron un escenario polarizado entre simpatizantes y detractores del nuevo gobierno chileno. Entre los primeros, el diario otorgó mayor visibilidad al peronismo, quien a través de distintos referentes interpretaba la victoria de la Unidad Popular como una señal de que "la hora de los pueblos" se acercaba, especulando incluso con la posibilidad de que el propio Perón se instalara en Santiago, en caso de que la dictadura no le permitiera radi-

${ }^{8}$ Cf. "Culminó la campaña proselitista para las elecciones nacionales en Chile", 2 de septiembre de 1970; "Finalizó la campaña proselitista en Chile", 3 de septiembre de 1970; "Hoy se elige un nuevo presidente en Chile", 4 de septiembre de 1970.

${ }^{9}$ Cf. "Frei advirtió que un nuevo feudalismo amenaza ahora a Chile", 22 de mayo de 1970.

${ }^{10}$ Cf. "Las elecciones chilenas", 4 de septiembre de 1970.

${ }^{11}$ En "Discurso de Allende; Alessandri y Tomic reconocieron el triunfo de Salvador Allende", "Allende prometió un gobierno sin espíritu de venganza. Manifestaciones de júbilo en Chile" y "Repercusiones del mundo marxista", 6 de septiembre de 1970.

${ }^{12}$ Cf. "El resultado electoral en la República de Chile", 8 de septiembre de 1970 y "Las nacionalizaciones chilenas", 29 de noviembre de 1970.

${ }^{13}$ Publicado el 13 de septiembre de 1970. 
carse en la Argentina: ${ }^{14}$ entre los segundos destacaban fundamentalmente a las Fuerzas Armadas que, a pesar del "silencio oficial", advertían que Chile constituiría "un área de peligro" para la Argentina debido a la estrecha relación mantenida entre Salvador Allende y Fidel Castro. ${ }^{15}$ Sin embargo, a pesar de este esquema binario que parecía interpretar la política trasandina a la luz del antagonismo peronismo-antiperonismo, las primeras expresiones oficiales de la dictadura transmitían una absoluta normalidad diplomática. Esto no se manifestaba solo en las felicitaciones del General Marcelo Levingston al nuevo presidente electo o en sus afirmaciones acerca de que era una cuestión "exclusivamente de Chile", desmintiendo la versión sobre una posible intervención argentina, sino también en la decisión de detener y deportar a ciudadanos chilenos sospechados de haber perpetrado el asesinato ${ }^{16}$ del general Schneider. ${ }^{17}$ De esta manera, la imagen que se desprendía de las páginas del diario era de dos gobiernos que privilegiaban el normal funcionamiento de sus relaciones diplomáticas por sobre sus marcadas diferencias ideológicas.

El clima de distensión y acercamiento iniciado a principios de 1970 se profundizó con la asunción del dictador Alejandro Agustín Lanusse (1971-1972). Como señalamos al comienzo del artículo, este contexto favorable para las relaciones binacionales se inscribía en el abandono de la estrategia de las "fronteras ideológicas", seguida por la cancillería argentina hasta ese momento, y su reemplazo por el "pluralismo ideológico”, el cual no solo se proponía abrir mercados en la región sino también equilibrar su capacidad de negociación frente a la política expansiva de Brasil (Rapoport, 2005; Zapata y Zurita, 2005).

En el marco de esta nueva concepción en materia de política exterior, en julio de 1971 se entrevistaron en la ciudad argentina de Salta los mandatarios Salvador Allende y Alejandro Agustín Lanusse. En un comienzo, la cobertura informativa de Río Negro transmitía cierto optimismo sobre los posibles resultados de la reunión, señalando que se trataría tanto cuestiones vinculadas a diferendos territoriales como temas de orden político, económico y cultural. ${ }^{18} \mathrm{El}$ diario destacaba la importancia de la entrevista, la cual calificaba como un "histórico encuentro", a la vez que resaltaba el "clima festivo" vivido en la ciudad norteña. Las crónicas periodísticas daban cuenta también que ambos mandatarios "inesperadamente" habían salido a caminar por las calles salteñas decidiendo entrar a una confitería para tomarse un café. ${ }^{19}$ Este tipo de notas que representaban a los presidentes en situaciones cotidianas, como si se tratarse de dos ignotos amigos, fueron habituales en la cobertura del Río Negro sobre los encuentros entre Lanusse y Allende. De esta forma el diario se plegaba acríticamente a la estrategia de escenificación

\footnotetext{
${ }^{14}$ Cf. "Conociéronse opiniones de políticos del país sobre el triunfo de Allende", 7 de septiembre de 1970; "Perón, de no poder entrar en el país se radicaría en Chile", 22 de septiembre de 1970 y "Perón se radicaría en Chile", 30 de noviembre de 1970.

${ }^{15}$ Cf. "El triunfo de Allende", 6 de septiembre de 1970 y "Conociéronse opiniones...", 7 de septiembre de 1970.

${ }^{16}$ A pocos días de que Salvador Allende fuera confirmado por el Congreso chileno como presidente, un grupo de ultraderecha asesinó al comandante en jefe de las Fuerzas Armadas René Schneider.

${ }^{17}$ Cf. "Levingston hizo anuncios sobre la futura actividad electoral", 25 de septiembre de 1970.

${ }^{18}$ Cf. "Canal de Beagle: Lanusse y Allende se reunirán antes de treinta días", 1 de julio de 1971; "Lanusse y Allende se reunirán en Bariloche", 17 de julio de 1971 y "Se reúnen el viernes en Salta, Lanusse y Allende", 21 de julio de 1971.

${ }^{19}$ Cf. "Lanusse y Allende en Salta", 24 de julio de 1971.
} 
de la política, tendiente a condensar en la gestualidad puesta en juego por los protagonistas la interpretación sobre una materia tan compleja como las relaciones exteriores. Las noticias sobre la declaración final de la entrevista destacaban la voluntad manifestada por los mandatarios de impulsar la integración física, económica y científica, al igual que el compromiso de fortalecer los vínculos de amistad entre ambos pueblos, basados en la histórica resolución pacífica y jurídica de las diferencias y en el respeto al "pluralismo político". La declaración incluía también la necesidad de incrementar los intercambios comerciales entre ambos países destacando la importancia que en los mismos debía alcanzar el sector industrial. ${ }^{20}$

Para el diario, los acuerdos de Salta constituían un cambio positivo en la política exterior argentina. En una de sus notas destacaba que Lanusse había quebrado la "línea político-militar" impulsada hasta el momento, la cual había tenido entre sus objetivos principales la conformación junto a Brasil de un "bloque atlántico de derecha" que enfrentara el "giro izquierdista" que estaba produciéndose en el Pacífico. ${ }^{21}$ En la sección "Semana política”, el Río Negro afirmaba que el gobierno argentino parecía haber archivado la teoría de las fronteras ideológicas, que durante cuatro años subsumieron su política exterior a la estrategia de la diplomacia brasileña, para aproximarse a los "regímenes nacionalistas" de la región. Celebrando este cambio, el diario señalaba las ventajas de emprender un proceso de integración con el bloque andino, conformado por países con una estructura económica diferente a la brasileña. El artículo distinguía entre el modelo industrial exportador, sostenido por este último, el cual requería de una política exterior agresiva y, el otro, que era impulsado por los "regímenes sociales modernos" del Pacífico, tendientes a alcanzar un desarrollo basado en el mercado interno que a su vez permitiera integrar a su población. En este marco, las "estériles" disputas fronterizas con Chile debían subsumirse a imperativos de trascendencia histórica como la integración de este bloque. ${ }^{22}$

En octubre de 1971, Alejandro Agustín Lanusse realizó una gira por los países andinos visitando el Perú de Velasco Alvarado y el Chile de Salvador Allende. Las noticias publicadas por el diario compartieron tanto la centralidad asignada a los presidentes y su adscripción ideológica, "nacionalista" o "socialista" según el caso, como la importancia que tuvieron la "cooperación" y la "autodeterminación", en tanto conceptos fundamentales de la articulación discursiva de los tres mandatarios.

Los artículos que abordaron la visita a Chile en particular, volvieron a referir a la importancia del encuentro de Salta, en tanto quiebre en las relaciones binacionales que permitió "desterrar" la doctrina de las "fronteras ideológicas" y resolver la cuestión del canal de Beagle, ${ }^{23}$ sometiendo la disputa a una corte arbitral. ${ }^{24}$ En esta reunión celebrada en Antofagasta, se incorporó a la agenda diplomática la firma de un convenio laboral que comprendía a los trabajadores chilenos en la Argentina, tema que Río

\footnotetext{
${ }^{20}$ Cf. "Finalizó la entrevista entre Lanusse y Allende, Suscribióse una declaración conjunta argentino-chilena", 25 de julio de 1971.

${ }^{21}$ Cf. "Repercusiones de la entrevista", 25 de julio de 1971.

22 Publicado en la fecha del 29 de julio de 1971.

${ }^{23}$ Desde el año 1904, la fijación del curso de este canal y el establecimiento de la soberanía sobre las islas ubicadas en la zona constituyó una cuestión pendiente en la agenda diplomática de ambas cancillerías. En 1967 el presidente chileno Eduardo Frei intentó resolver el diferendo apelando al arbitraje de la corona británica que la dictadura del General Juan Carlos Onganía se negó a aceptar.

${ }^{24}$ Cf. "Lanusse y Allende están reunidos en Antofagasta", 17 de octubre de 1971.
} 
Negro destacó en su primera plana como uno de los principales logros del encuentro. ${ }^{25}$ Esto no resulta extraño si consideramos la histórica importancia que ha tenido la migración chilena en la región, sumado al hecho de que para la elite norpatagónica, de la cual formaba parte la familia propietaria del Río Negro, la fuerza de trabajo trasandina constituía un eslabón fundamental para la sustentabilidad de su actividad principal: la fruticultura.

$\mathrm{Al}$ igual que en Salta, en su cobertura informativa sobre la reunión en Antofagasta el diario destacó la relación personal entre los mandatarios, la cual lo diferenció claramente del tono protocolar que primó en las noticias sobre la visita del dictador argentino a Perú. En este sentido, las fotos de Salvador Allende acomodando el micrófono del general Lanusse, las que registraron la despedida de los mandatarios y sus esposas en el aeropuerto, junto con las que dieron cuenta de la decisión del "masón y marxista" presidente chileno de acompañar a su "gran amigo" Lanusse a la misa, contribuyeron a reforzar la imagen de que entre ambos existía un sólido y estrecho vínculo personal. ${ }^{26}$

Para los lectores de Río Negro, este espíritu de confraternidad que recorrió las noticias sobre las relaciones binacionales adquirió en el espacio norpatagónico una dimensión más cercana y concreta. En este escenario informativo las noticias referidas al acercamiento a Chile profundizaron sus aspectos económicos reinstalando los proyectos de integración física y comercial. En sus editoriales, el diario destacaba las "brillantes posibilidades" que brindaría para el comercio regional y la explotación del "circuito turístico internacional" la construcción de rutas en la franja cordillerana, luego de que Vialidad Nacional declarara el carácter prioritario de los pasos internacionales de las provincias de Río Negro y Neuquén. Según Río Negro la concreción de estas obras constituiría un avance concreto en función de los acuerdos alcanzados en la entrevista de Salta. ${ }^{27}$ Esta perspectiva se reforzaba con las noticias sobre el Consejo de Planificación y Acción para el Desarrollo y sus análisis sobre incrementar los intercambios comerciales entre la zona del Alto Valle y Neuquén con el mercado chileno y los países del Pacífico. Asimismo, las noticias que dieron cuenta de la profundización de los vínculos binacionales no se agotaron en la esfera económica. Las crónicas sobre los festejos de la independencia trasandina, que año a año publicaba el diario visibilizando la presencia y arraigo de la comunidad chilena en la región, daban cuenta de una dimensión simbólica de este acercamiento al referir a la "emotiva ceremonia" a través de la cual una escuela neuquina había sido bautizada con el nombre de "República de Chile". ${ }^{28}$ En este punto cabe destacar que si bien para los lectores del Río Negro las noticias sobre estrechos vínculos binacionales en el espacio norpatagónico no constituían novedad alguna, lo que sí evidenciaba un cambio en relación con los primeros años de la Revolución Argentina era la centralidad que asumían las agencias estatales en tanto promotoras de los mismos.

En otro orden de cosas, los distintos análisis políticos que circularon por las páginas del diario coincidían en inscribir el viaje de Lanusse por Chile y Perú en la estrategia de

\footnotetext{
${ }^{25}$ Cf. "El presidente Lanusse finalizó la gira", 18 de octubre de 1971.

${ }^{26}$ Cf. "Allende acompañó a misa a Lanusse", 18 de octubre de 1971.

${ }^{27}$ Cf. "Comercio y turismo con Chile", 5 de septiembre de 1971.

${ }^{28}$ Cf. "Intercambio con Chile", 2 de noviembre de 1971; "Aniversario de Chile", 19 de septiembre de 1971 y "Fiestas chilenas", 19 de septiembre de 1971.
} 
la cancillería argentina de consolidar un bloque de naciones del cono sur. ${ }^{29}$ Sin embargo, estas interpretaciones también incorporaban una dimensión más doméstica referida a la intención de Lanusse de construir su candidatura presidencial de cara a una futura convocatoria a elecciones. En este sentido, un enviado especial del diario sostenía que el "giro populista" evidenciado en las entrevistas con Velasco Alvarado y Salvador Allende se enmarcaba en la estrategia del dictador de construir una "imagen de popularidad" ${ }^{30}$ En este punto, es importante señalar que a pesar del explícito apoyo del diario al cambio en política exterior implementado por el general Lanusse, el Río Negro mantuvo posiciones críticas sobre la pervivencia de la dictadura en momentos que, según afirmaba, el conflicto político en la Argentina solo podría resolverse rehabilitando los canales de participación constitucional. ${ }^{31}$ En su espacio editorial, a la vez que destacaba la importancia del encuentro de Salta, en tanto materialización del abandono de la estrategia impuesta por Onganía, el diario advertía sobre la necesidad de una pronta convocatoria a elecciones. ${ }^{32}$ Esta demanda se reiteraría durante la gira del presidente de Lanusse por Chile y Perú, al sostener que poco podía ofrecer a los "países vecinos" un "presidente que carece de mandato popular" ${ }^{33}$ Estas críticas se expresaron también mediante el humor gráfico ironizando sobre las contradicciones de la nueva política exterior adoptada por el presidente de facto (ver Figura 1).

En síntesis, la asunción de Lanusse pareció consolidar el cambio en materia de política exterior que comenzó a vislumbrarse hacia fines del onganiato. En este contexto, las frecuentes noticias sobre tensiones con Chile, que en ocasiones respondían a la tesis de las "fronteras ideológicas" y en otras al ancestral temor del nacionalismo territorial, dieron paso a los discursos intergracionistas impulsados por la nueva orientación exterior de la cancillería argentina. A pesar de sus críticas hacia el gobierno nacional, el Río Negro celebró este cambio de política exterior que posibilitaba que la dictadura de Lanusse estrechara sus vínculos con el gobierno del presidente socialista Salvador Allende. Sin embargo, los conflictos que se suscitaron tras los hechos de Rawson y Trelew revelarían la imposibilidad de soslayar las profundas diferencias políticas que existían entre ambos gobiernos, como pretendía el "pluralismo ideológico" promovido por el dictador Lanusse.

\footnotetext{
${ }^{29}$ Cf. "Argentina incrementará con Chile y Perú el intercambio comercial", 11 de octubre de 1971; "Lanusse deja hoy el Perú y se traslada a Chile", 16 de octubre de 1971; "Fue suscrita la declaración conjunta argentino-peruana", 17 de octubre de 1971.

${ }^{30}$ Cf. “¿Lanusse candidato a presidente?”, 21 de octubre de 1971.

${ }^{31}$ En este punto cabe recordar que en esos años la Norpatagonia también fue escenario de movilizaciones enmarcadas en el proceso de efervescencia social que atravesaba el país. Entre fines de 1969 y principio de 1970 los obreros afectados a la construcción de la represa de El Chocón se rebelaron ante los magros sueldos y las pésimas condiciones (Mases, Rafart, Lvovich y Quintar, 1998). Por su parte, en 1969 y 1972 también se produjeron dos importantes puebladas en las ciudades rionegrinas de Cipolletti y General Roca, que si bien fueron de naturaleza distinta, tanto por su composición social heterogéneas como por ser una disputa intrarregional más que una impugnación a la dictadura, no por ello dejaron de ser expresión del clima de movilización social que imperaba en el país (Tapia, 2012; Yappert y Bohoslavsky, 2012).

${ }^{32}$ Cf. "Las fronteras", 31 de julio de 1971.

${ }^{33}$ Cf. "Los viajes del presidente al exterior", 16 de marzo de 1972.
} 


\section{La fuga de Trelew y la ideologización de las relaciones binacionales}

En 1972 se produjo un incidente que evidenció el complejo entramado en el que se insertaba la cordial convivencia que pretendía sostener la dictadura de Alejandro Agustín Lanusse y el gobierno de Salvador Allende. El 15 de agosto de ese año, veinticinco presos políticos ${ }^{34}$ se fugaron del penal argentino de Rawson, seis de los cuales lograron huir hacia Chile en un avión secuestrado por compañeros que se encontraban en libertad, mientras que los restantes tomaron el aeropuerto de esa ciudad para negociar su rendición. Este hecho no solo golpeó la imagen pública de la dictadura sino también colocó al presidente chileno frente a un difícil dilema en el que se ponían

Figura 1: Caricatura política publicada por Río Negro

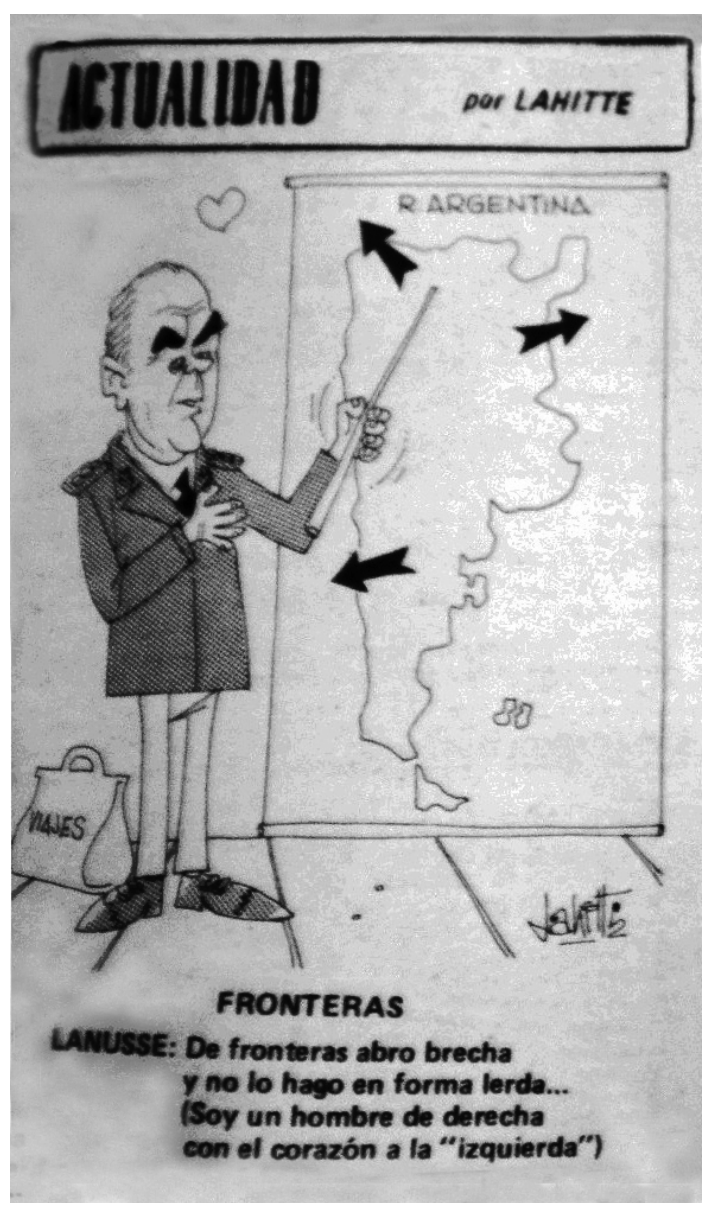

Nota: Las caricaturas políticas publicadas por Río Negro en la sección "De actualidad" eran de Carlos Alberto Lahitte, dibujante bahiense que también publicaba en el diario La Nueva Provincia.

Fuente: Río Negro, 21 de octubre de 1971.

\footnotetext{
${ }^{34}$ Los detenidos integraban las organizaciones guerrilleras Montoneros, Fuerzas Armadas Revolucionarias (FAR) y el Ejército Revolucionario del Pueblo (ERP). Estos grupos surgidos entre los años 1969 y 1970 compartieron la convicción de que el sistema de dominación vigente, de tipo semicolonial, reposaba en la violencia y que solo otra violencia podría derrotarlo (Altamirano, 2007, pp. 123-124).
} 
en juego distintas tramas de sentido: priorizar sus buenas relaciones con el "gobierno argentino" extraditando a "delincuentes fugados" de una cárcel, o reconocerlos como "luchadores populares" que resistían a una de las tantas "dictaduras" brindándoles asilo político. Al cumplirse una semana de la fuga del penal de Rawson, los presos políticos que se rindieron en el aeropuerto y que estaban detenidos en la base Almirante Zar, en la ciudad patagónica de Trelew, fueron fusilados en sus celdas bajo el pretexto del intento de fuga. Este crimen cambiaría en forma dramática el escenario de negociación entre la dictadura argentina y el gobierno chileno.

En un comienzo, las noticias sobre la fuga publicadas por Río Negro se enmarcaron en el género policial velando sus aristas más políticas. Operaba de esta forma un deslindamiento que establecía una división entre legalidad e ilegalidad, principio a partir del cual se regulaban y jerarquizaban los distintos discursos. ${ }^{35}$ Esta cobertura informativa definía un nosotros comprendido por aquellos que estaban dentro de la ley mientras que el ellos designaba a los grupos que habían decidido violarla por motivos que no acababan de expresarse con claridad. De esta forma, el esquema clasificatorio que se ponía en juego establecía un campo binario en el que antagonizaban "extremistas" y "fuerzas del orden"36 (Azcoitia, 2014).

Este principio interpretativo, funcional al discurso de la dictadura, se prolongaba hacia las noticias referidas a la situación de los "extremistas" que habían escapado a Chile. En este escenario informativo, el diario representaba a Salvador Allende como un presidente ante el dilema de optar por el camino de la "legalidad" y extraditar a los "extremistas", fortaleciendo así las relaciones con la Argentina, o romper los compromisos asumidos y otorgarle asilo político a los "fugados", "cediendo" a las "presiones" de la izquierda de su país. En este sentido, las primeras noticias presentaban a distintos miembros del gobierno chileno, entre los que se encontraba el propio presidente, sosteniendo que la decisión sobre el pedido de extradición realizado por la Argentina, bajo el cargo de "piratería aérea y otros delitos comunes", era competencia de la Corte Suprema de Justicia. Por su parte, distintos artículos advertían insistentemente sobre la preocupación de los funcionarios de la dictadura argentina por la "demora" en la respuesta del gobierno chileno pero sin poner en duda que todo acabaría finalmente con la extradición de los "extremistas" ${ }^{37}$ En este marco, la posibilidad de que los

\footnotetext{
${ }^{35}$ Michel Foucault acuñó el concepto de orden del discurso para señalar que en las sociedades los discursos no circulan libremente sino que pueden descubrirse condiciones que regulan su producción y circulación, a través de normas y procedimientos de control establecidas por aquellos colectivos con poder para hacerlo. En las sociedades de discurso los procesos de exclusión generalmente no implican la anulación del discurso del otro sino a través de los procedimientos de deslindamiento y de rechazo. El deslindamiento supone establecer una oposición entre dos términos, uno representando la "normalidad" y el otro la "anormalidad", actuando en última instancia sobre la oposición "nosotros" y "ellos". El rechazo entraña la construcción de una imagen negativa sobre la base de unas normas o reglas que puedan hacerse o no explícitas, pero que, en cualquier caso, son evocadas (Martín, 1997).

${ }^{36}$ Amossy y Herschberg afirman que las representaciones colectivas cristalizadas juegan un papel fundamental en la cohesión del grupo y en la consolidación de su unidad, el estereotipo aparece ante todo como un instrumento de categorización que permite distinguir cómodamente un "nosotros" de un "ellos" (Amossy y Herschberg, 2001).

${ }^{37}$ Cf. "Adquirió un cariz sangriento el dramático episodio que se vivió en el penal de Rawson" y "Se entregaron en Chile los que lograron huir en avión", 18 de agosto de 1972; "Chile: Allende afronta una difícil situación", "El gobierno afronta distintas presiones", 19 de agosto de 1972; "Detienen en Trelew a un dirigente radical", 20 de agosto de 1972; "Chile: sin definir aun el caso de los evadidos de Rawson" y "Chile: confuso panorama en torno de la situación de extremistas argentinos", 21 de agosto de 1972; "Chile: interrogarían a los extremistas", 22 de agosto de 1972.
} 
"fugados" continuaran su viaje hacia Cuba o Argelia circulaba como "versiones" pero sin que se le concediera mayor relevancia. Sin embargo, días antes de que se produjeran los fusilamientos un vocero de la cancillería chilena había advertido que si bien la extradición era una decisión que competía a la Corte Suprema, los tratados internacionales eximían de su cumplimiento en los casos de "certeza o presunciones serias, de que los eventualmente sometidos a extradición sufrieran pena de muerte en su país" ${ }^{38}$ Resulta sugestivo que a pesar de la importancia que adquiriría esta definición para comprender el curso que tomaría el conflicto, en los días sucesivos el diario, no volviera a referir a esta oportuna aclaración.

Las noticias referidas a las repercusiones en Chile estuvieron atravesadas por la tensión entre quienes se identificaban como parte de un colectivo que incluía a los "compañeros" detenidos y aquellos que los definían como "criminales" o "terroristas" que debían ser extraditados. El Río Negro colocaba entre los primeros, tanto a los "jóvenes" del Movimiento de Izquierda Revolucionaria, como a conspicuos miembros del Partido Socialista, que por ese entonces representaban el sector más radicalizado de la Unidad Popular. ${ }^{39}$ Antagonizando con esta posición, emergía el diario conservador $E l$ Mercurio, quien sostenía que:

La admisión generosa de extremistas extranjeros, la divulgación de la creencia en el exterior de que Chile es un país abierto para los agitadores que combaten contra los gobiernos o sus pueblos, y la ilusión de que deben los chilenos manifestarse solidariamente con las guerrillas, han conducido a problemas difíciles. Este criterio ha permitido que tengamos muchos huéspedes indeseables. ${ }^{40}$

Por su parte, al igual que las noticias referidas a la fuga, en las páginas del Río Negro la posición de la dictadura argentina también se situaba del lado de la legalidad, apelando a los acuerdos internacionales que avalaban el pedido de extradición.

Sin embargo, al cumplirse una semana de la fuga de Rawson la situación cambió radicalmente. En la madrugada del 22 de agosto, los 19 prisioneros políticos detenidos en la base Almirante Zar fueron fusilados en sus celdas bajo el pretexto de un intento de fuga. En este nuevo escenario abierto después del asesinato perpetrado por las Fuerzas Armadas, el gobierno de Salvador Allende tomó la decisión de otorgar un salvoconducto a los seis argentinos asilados que les permitió abandonar suelo chileno para partir hacia Cuba.

Para Río Negro la matanza perpetrada por quienes debían ser garantes del orden tensionaba el principio interpretativo mantenido hasta el momento, colocando a las Fuerzas Armadas del lado de la ilegalidad. En este nuevo escenario irrumpieron lecturas que inscribían el hecho en otras tramas de sentido, dejando de representar el conflicto solo en clave jurídica para revelar su verdadera naturaleza política (Azcoitia, 2014). A pesar de ello, en la cobertura informativa sobre el pedido de extradición continuó predominando una perspectiva "legalista" que se desplegó sin matices

\footnotetext{
${ }^{38}$ Cf. "Chile: los extremistas están a disposición de la Suprema Corte", 18 de agosto de 1972.

${ }^{39}$ C.f. "Adquirió un cariz sangriento el dramático episodio que se vivió en el penal de Rawson", 18 de agosto de 1972; "Se entregaron en Chile los que lograron huir en avión", 18 de agosto de 1972; "Chile: Allende afronta una difícil situación", 19 de agosto de 1972; "El gobierno afronta distintas presiones", 19 de agosto de 1972; "Detienen en Trelew a un dirigente radical”, 20 de agosto de 1972.

${ }^{40}$ Cf. "Comentario periodístico", 19 de agosto de 1972.
} 
condenando la decisión del gobierno chileno de otorgar el salvoconducto a los fugados que les permitió continuar su viaje hacia Cuba. Si bien, como se ha expuesto, en los días previos la cancillería trasandina había advertido que el cumplimiento de los tratados internacionales se encontraba supeditada a que los extraditados no "...sufrieran pena de muerte", cuestión que Lanusse claramente no estaba en condiciones de asegurar después de los fusilamientos, este argumento estuvo ausente en los artículos que intentaron explicar los motivos que impulsaron la decisión del gobierno de Salvador Allende. ${ }^{41}$ Las noticias sobre la partida de los "extremistas" hacia la Habana no hizo ninguna referencia al radical cambio de escenario generado por la matanza perpetrada en Trelew, del que sí daban cuenta al cubrir el tema en el plano nacional. Esta dualidad en el análisis permitía a Río Negro responsabilizar a la dictadura por los asesinatos en la base Almirante Zar a la vez que avalaba sus reclamos ante el gobierno chileno, sin establecer relación alguna entre un escenario informativo y otro. ${ }^{42}$

Las páginas del diario rionegrino explicaban la decisión de otorgar el salvoconducto centrando las responsabilidades en la figura de Salvador Allende, construido como un presidente que finalmente había cedido ante las presiones de la extrema izquierda. Los artículos enfatizaban una y otra vez que el presidente chileno "intempestivamente" había cambiado de decisión, culpabilizándolo de quebrar el tradicional respeto que ambos países habían mantenido ante los compromisos y acuerdos binacionales. ${ }^{43}$ En este punto es importante señalar que al centrar las críticas en la figura presidencial, las noticias inscribían el antagonismo en un escenario ideológico-político y no nacional. En otras palabras, para el diario la explicación de que Allende hubiera incumplido con los compromisos internacionales asumidos, no se hallaba en su condición de "chileno", argumento que se hubiera esgrimido desde una matriz nacionalista territorial, inscribiendo esta decisión en una supuesta genealogía de "traiciones de nuestros vecinos", sino en la orientación "socialista" de su gobierno.

El Río Negro reforzó esta construcción recontextualizando artículos publicados en la prensa nacional e internacional, lo que le permitía configurar un efecto de unanimismo o consenso en torno al "incumplimiento" del presidente socialista. En este sentido, el diario colombiano El Espectador advertía que a pesar de la cordialidad alcanzada "entre marxistas y militares" la decisión del gobierno de la Unidad Popular podría hacer ingresar las relaciones "en una zona oscura y azarosa" por tener "fronteras comunes y diferencias políticas muy netas [...] entre un ideólogo marxista y un general de carrera" ${ }^{44}$ Por su parte, "el influyente diario liberal" El tiempo, de Bogotá, calificaba al salvoconducto como "un error garrafal" por provocar "una brecha" que iba a ser "muy difícil salvar". ${ }^{45}$ Entre los diarios nacionales, el Río Negro recurrió a La Nación, quien calificaba la decisión como "desafortunada" sosteniendo que probablemente alteraría "el diálogo inteligente y fecundo" que habían mantenido ambos países "por encima de cualquier discrepancia circunstancial en el orden de las doctrinas inspiradoras de su acción política”. Para este diario (La Nación), el conflicto se había originado

\footnotetext{
${ }^{41}$ Cf. "Chile: los extremistas están a disposición de la suprema corte", 18 de agosto de 1972.

${ }^{42}$ Cf. "La sombra en la pared", 24 de agosto de 1972.

${ }^{43}$ Cf. "Podrían abandonar Chile los diez fugados", 24 de agosto de 1972.

${ }^{44} \mathrm{Cf}$. "El gobierno chileno estudia la respuesta que dará a la formal protesta argentina", 29 de agosto de 1972.

${ }^{45}$ Cf. "Colombia: comentan la situación entre Argentina y Chile", 31 de agosto de 1972.
} 
simplemente porque Allende no aplicó "las normas del derecho" por presión de "los grupos sectarios [...] que visten de un colorido ultraizquierdismo". Sostenía que para los prófugos las fricciones entre ambos países carecían de importancia porque "... sus lealtades se limitan a los dogmas que los fanatizan y los nivelan en el odio". ${ }^{46}$

Por su parte, Juan Domingo Perón emergía de las páginas de Río Negro destacando la figura del presidente trasandino por cumplir sus compromisos afirmando que "los que luchamos por la libertad tengamos confianza en los gobiernos que representan al pueblo" ${ }^{47}$ Sin embargo, la voz de los fugados parecía sintonizar mejor con la versión dominante en las páginas del Río Negro al afirmar que la extradición había sido posible "por la movilización del pueblo de Chile" que había permitido superar las "vacilaciones" del "compañero Salvador Allende". Esta divergencia en torno a las lecturas sobre el proceso chileno manifestaban las profundas discusiones que estaban produciéndose en el seno del justicialismo y que, como veremos, eclosionarían con fuerza a partir de 1973 .

Finalmente, hacia el mes de septiembre de 1972 las noticias daban cuenta de la normalización de las relaciones binacionales. El regreso del embajador argentino a Santiago fue interpretado por la prensa como una "superación total" del conflicto suscitado por los "extremistas" asilados. ${ }^{48}$ En las páginas del diario rionegrino podían leerse las palabras de representantes del gobierno chileno expresando su "voluntad de estrechar aún más los lazos" de amistad entre ambos países, definiendo el incidente como una "circunstancial divergencia". ${ }^{49}$

Como hemos señalado, hasta agosto de 1972 las noticias sobre las relaciones argentino-chilenas prescindieron de las adscripciones ideológicas de los gobiernos, las cuales apenas habían constituido una referencia descriptiva más que explicativa. Sin embargo, a partir del incidente generado tras la fuga de Rawson se evidenció en el diario la creciente preeminencia que fue adquiriendo esta dimensión en la construcción informativa de la agenda binacional.

En este sentido, las relaciones entre Argentina y Chile volvieron a tensarse luego de que la dictadura de Alejandro Agustín Lanusse decidiera brindarle asilo político a Walter Roberto Thieme, uno de los referentes principales de la organización ultraderechista "Patria y Libertad". En cuanto a la cobertura informativa de esta situación, resulta sugestivo que Thieme fuera representado simplemente como "un singular personaje" o como "un joven dirigente derechista opositor al gobierno de Allende", siendo que en el propio Río Negro podía leerse que había simulado su muerte "... para poder dedicarse con más comodidad a organizar una conspiración armada tendiente a derrocar al gobierno" y también que la organización que conducía se identificaba con la cruz gamada y al "culto a la violencia". Esta caracterización de un "exindustrial, casado con tres hijos" que la "prensa izquierdista chilena" acusaba de contrabandear armas "...para apoyar un golpe de Estado" ${ }^{50}$ contrastaba visiblemente con el empleo sistemático del anatema "extremista" utilizado profusamente por el diario para refe-

\footnotetext{
${ }^{46}$ Cf. "Comentarios acerca de la decisión chilena de dar asilo a extremistas", 29 de agosto de 1972.

${ }^{47}$ Cf. "Refirióse Perón a los episodios de Trelew", 29 de agosto de 1972.

${ }^{48}$ Cf. "Reasumió el embajador argentino en Chile", 25 de septiembre de 1972.

${ }^{49}$ Cf. "Respondió Chile a la protesta argentina", 8 de septiembre de 1972.

${ }^{50}$ Cf. "Concedieron asilo político a los dos chilenos detenidos en Mendoza", 8 de mayo de 1973; "Uno de los asilados políticos habla de su salida de Chile", 13 de mayo de 1973.
} 
rirse a los involucrados en la fuga de Rawson, apenas unos meses antes. Esta estrategia de matizar el carácter golpista del personaje se complementaba con la ausencia de artículos que cuestionaran el hecho de que la dictadura le hubiera otorgado asilo político. En este sentido, el diario simplemente se limitó a explicar los motivos de la decisión del gobierno argentino empleando un argumento ideológico, basado en “... la simpatía profunda que las FFAA tiene por movimientos del tipo Patria y Libertad”, y otro diplomático, referido a una devolución de "gentilezas" al gobierno chileno por el incidente de Trelew. ${ }^{51}$

Pese a las tensiones generadas por esta situación, las noticias sobre la presencia del presidente Allende en la asunción de Héctor J. Cámpora no solo volvieron a instalar el tono cordial que había predominado en los encuentros de Salta y Antofagasta, sino que revelaron también un cambio cualitativo en los discursos sobre los vínculos binacionales imprimiéndoles mayor densidad política sobre la base de la necesidad de una integración "antiimperialista".

Para comprender este nuevo contexto es necesario revisar las transformaciones por las que atravesó el peronismo durante las décadas de los sesenta y setenta. En la Argentina, la revolución cubana había tendido un puente entre nacionalismo, socialismo y peronismo mostrando que en Latinoamérica los movimientos nacionales y no los partidos comunistas serían quienes conducirían a sus pueblos al socialismo. En el marco de esta versión radicalizada "socialismo", "peronismo" y "lucha antiimperialista" fueron configurando un mismo campo semántico (Sigal, 1991; Sigal y Verón, 2008). La propia designación de Héctor Cámpora como candidato del Frente Justicialista de Liberación (FREJULI) ${ }^{52}$ parecía responder a esta nueva demanda, desplazando al sector sindical del partido en favor de las ramas política y juvenil. Esta última se constituyó en la gran protagonista de la campaña presidencial que acabó con el triunfo de marzo de 1973 (Nahmías, 2013; Riz, 1981).

Este universo discursivo compartido por sectores radicalizados del FREJULI y el gobierno de la Unidad Popular se plasmaba en las páginas de Río Negro a través de titulares y fotos de tapa que señalaban la importancia y popularidad de Allende, destacándolo por encima del resto de las delegaciones que asistieron a la asunción de Cámpora, a excepción de la del presidente cubano Osvaldo Dorticós (1959-1976). ${ }^{53}$ Las noticias daban cuenta tanto de la nutrida presencia juvenil que acompañaba los movimientos del mandatario trasandino, como de los cánticos en su favor vinculando los procesos políticos chileno y cubano con el que acababa de iniciarse en la Argentina. ${ }^{54}$

En esos días, por las páginas de Río Negro circuló profusamente un potente discurso antiimperialista que bogaba por la unidad latinoamericana. Se inscribían en esta línea las palabras de Salvador Allende celebrando el "reencuentro de la Argentina con un gobierno popular" y destacando la trascendencia de un cambio que permitiría

\footnotetext{
${ }^{51}$ Cf. "Chile: Thieme, un personaje singular de la ultraderecha", 21 de mayo de 1973.

${ }^{52}$ Este frente estuvo integrado por el Partido Justicialista, el Movimiento de Integración y Desarrollo, el Partido Popular Cristiano, Conservador Popular, y Laborista, junto a una multiplicidad de partidos provinciales. Su triunfo en las elecciones de 1973 puso fin a la larga proscripción del peronismo que se había iniciado tras el golpe de 1955.

${ }^{53}$ Cf. "Allende viaja hoy a la Argentina", "Se aguarda el arribo de Allende y Dorticós", 23 de mayo de 1973; "Dorticó es esperado hoy", 24 de mayo de 1973.

${ }^{54}$ Cf. "Hoy llegaría Dorticós", 24 de mayo de 1973; "Tendremos en pocos años la Argentina liberada", 26 de mayo de 1973.
} 
a la región marchar "unida hacia su liberación". ${ }^{55} \mathrm{El}$ presidente chileno evocaba el "mandato de los próceres" afirmando que se debía luchar por una América "integrada, independiente y soberana" ${ }^{56} \mathrm{El}$ discurso de Héctor Cámpora sintonizaba con estas demandas al asumir el compromiso de propugnar la "cooperación estrecha con los países del Tercer Mundo y especialmente con los de América Latina”. En este sentido, el mandatario argentino cuestionaba también el rol de la Organización de Estados Americanos afirmando que esta institución se encontraba en crisis y que no servía "a los fines de la liberación" de los pueblos de la región. ${ }^{57}$

\section{El repudio al golpe en Chile y el temor por la izquierda revolucionaria}

Pese al optimismo generalizado que los discursos antiimperialistas de Allende y Cámpora parecían transmitir, en los meses subsiguientes, el contexto político cambiaría radicalmente a uno y otro lado de la cordillera. En la Argentina, las demostraciones de fuerza de la izquierda peronista contribuyeron a generar un clima de crisis de autoridad que favoreció a los sectores de la derecha que presionaban por el retorno de Juan Domingo Perón. Desde la perspectiva del líder del movimiento, la situación requería de la reconstrucción del poder del Estado, la cual solo se alcanzaría con la intervención de los partidos políticos, la burocracia sindical y las Fuerzas Armadas (Riz, 1981). Finalmente los enfrentamientos del 20 de junio de 1973 en el aeropuerto de Ezeiza revelaron la profundidad de las tensiones que venía desplegándose dentro del peronismo. ${ }^{58}$ Silvia Sigal y Eliseo Verón (2008) afirman que durante el exilio de Perón este conflicto se había expresado bajo la forma de adhesiones a diferentes palabras del líder, sin embargo una vez en el país solo podía haber una única palabra, su palabra pública, y ella denunciaría al "enemigo interno" que en Ezeiza había asesinado a los verdaderos peronistas. El 21 de junio, al día siguiente de los acontecimientos, el líder del movimiento pronunció un discurso en el que habló de los infiltrados, sin realizar ninguna mención sobre la matanza (Sigal y Verón, 2008, pp. 165 y 168). En este nuevo escenario abierto con el retorno de Perón, Héctor Cámpora debió renunciar a la presidencia y su lugar fue ocupado por Raúl Lastiri (1973), comenzando el ascenso del círculo de políticos que habían rodeado al viejo líder en los últimos años de su $\operatorname{exilio}^{59}$ (Riz, 1981).

\footnotetext{
${ }^{55}$ Cf. "Actividades de delegaciones del extranjero", 25 de mayo de 1973.

${ }^{56}$ Cf. "Cámpora y Allende reuniéronse ayer", 28 de mayo de 1973; "Allende: hay que luchar por una América soberana", 29 de mayo de 1973.

${ }^{57}$ Cf. "Exigiré respeto y obediencia de todo el personal militar", 26 de mayo de 1973.

${ }^{58}$ En el marco del acto organizado por el retorno definitivo de Juan Domingo Perón, grupos de la derecha peronista abrieron fuego contra una columna de Montoneros y Fuerzas Armadas Revolucionarias que intentaba acercarse al palco, lo que desató una batalla campal. Ezeiza se constituyó en escenario del enfrentamiento entre dos transversalidades dentro del peronismo, una de derecha y la otra de izquierda (Nahmías, 2013).

${ }^{59}$ Como presidente de la Cámara de Diputados Raúl Lastiri era el tercero en la línea sucesoria y ante la renuncia de Héctor Cámpora y su vice Solano Lima, asumió la presidencia el 13 de julio de 1973 finalizando su breve mandato el 11 de octubre del mismo año. Al día siguiente Juan Domingo Perón asumió como presidente por tercera vez. Lastiri era yerno de José López Rega, ministro de Bienestar Social y futuro responsable de la Alianza Anticomunista Argentina, organización paramilitar de extrema derecha.
} 
Paralelamente al complejo panorama político planteado en la Argentina, la profundidad de la crisis chilena parecía no tener límites. Entre los meses de mayo y septiembre de 1973 las páginas de Río Negro daban cuenta de un delicado escenario donde el estallido de una guerra civil se presentaba como un peligro cierto. ${ }^{60}$ En agosto, el presidente convocó nuevamente a los militares para conformar otro gabinete de gobierno; sin embargo, esta estrategia que había permitido mitigar la crisis política de 1972, resultó incapaz de frenar el conflicto en un contexto en que el gobierno prácticamente no gobernaba, el pueblo se había desmovilizado y los generales eran desobedecidos por sus subordinados. La oposición parlamentaria se pronunció en contra del nuevo gabinete y ante la presión de la oficialidad el general Carlos Prats debió renunciar, siendo reemplazado por el general Augusto Pinochet como comandante en jefe del ejército de Chile (Mires, 1989). Finalmente el 11 de septiembre de 1973 un golpe de Estado derrocó al gobierno democrático de la Unidad Popular terminando con la vida del presidente Salvador Allende. En su primera aparición pública como miembro de la Junta de Gobierno, el comandante en jefe de la Fuerza Aérea chilena, Gustavo Leigh Guzmán, explicitó parte del fundamento ideológico del nuevo gobierno al afirmar que el país se encontraba en guerra y que la mayoría del pueblo chileno estaba “...dispuesto a extirpar el cáncer marxista hasta las últimas consecuencias” (Valdivia, 2010, p. 166).

Desde un primer momento, el Río Negro condenó el golpe de Estado enfatizando en los titulares el carácter "popular" del gobierno derrocado. En su espacio editorial se identificaba con la compleja situación existente más allá de la cordillera afirmando que los lazos históricos y la larga frontera que unía a ambos países hacían del "drama chileno" un "...problema nacional...". A pesar de ponderar la figura de Salvador Allende el diario no dudaba en responsabilizar a su gobierno por no hallar "soluciones concretas a los problemas coyunturales", afirmando que había sido revolucionario en el "terreno ideológico" pero "desoladamente ineficaz" en la práctica. Esta situación, sumada al "sectarismo recíproco" que "llenó de odio la vida política", permitía comprender la "impotencia" del sistema para "resolver la agresividad de los bandos". El diario advertía con preocupación que en este nuevo escenario que se abría en Chile la izquierda hallaría "justificación total a su apelación a la violencia". ${ }^{61}$

En la superficie redaccional del Río Negro hubo un evidente predominio de discursos que condenaron la interrupción del "gobierno popular", exaltando fundamentalmente la figura del presidente depuesto. Las primeras noticias calificaban al golpe de "cruento" y describían la situación como "caótica" y "desoladora" ${ }^{62}$ Las páginas del diario rionegrino configuraban un escenario de confrontación entre la junta militar gobernante, que se constituía discursivamente como el responsable de haber liberado a "la nación del yugo marxista", y la resistencia armada de los "trabajadores" en las "barriadas" y en los "cordones fabriles", junto con los "francotiradores de izquierda" apostados en los edificios. ${ }^{63} \mathrm{El}$ diario publicó incluso versiones que circularon en la

\footnotetext{
${ }^{60}$ Cf. "Chile: parece acentuarse de hora en hora el peligro de una guerra civil", 26 de junio de 1973.

${ }^{61} \mathrm{Cf}$. "El fin de una experiencia", 17 de septiembre de 1973.

${ }^{62}$ Cf. "Golpe de Estado en Chile: las FFAA asumieron el poder en Chile", 12 de septiembre de 1973; "Lucha en Chile", 13 de septiembre de 1973; "Desolador panorama en Chile", 15 de septiembre de 1973.

${ }^{63}$ Cf. "Enfrenta resistencias el régimen militar chileno", 13 de septiembre de 1973; "Confusa situación en el vecino país", 14 de septiembre de 1973; "Chile vive un clima de confusión", 15 de septiembre de 1973.
} 
Argentina sobre el avance hacia Santiago de dos columnas al mando de Carlos Prats, integradas por militares y obreros, las cuales fueron desmentidas rápidamente tras el ingreso del general chileno a la Argentina. ${ }^{64} \mathrm{Si}$ bien para los lectores de Río Negro las calles de Chile parecían próximas a convertirse en escenario de una batalla decisiva en la lucha de clases, al concluir la primera semana de dictadura, la información periodística transmitía que los focos de resistencia se encontraban prácticamente controlados. ${ }^{65}$ Antes que finalizara el mes de septiembre las noticias sobre la muerte de Neruda, la prohibición de los partidos "marxistas" y de la Central Única de Trabajadores, sumadas a la abrumadora información periodística sobre fusilamientos, denuncias de torturas y detenciones, daban cuenta de la profundidad del cambio que comenzaba a imponerse allende la cordillera. ${ }^{66}$

En las páginas de Río Negro la Norpatagonia constituyó otro escenario que aportaba claves para interpretar las derivaciones políticas en Chile. Las notas sobre las diferentes reacciones en la región generaban un efecto de unanimismo o consenso en torno al repudio al golpe. Los gobiernos provinciales de Río Negro y Neuquén, junto a sus respectivas cámaras legislativas; la Iglesia católica; la regional de la Confederación General del Trabajo, el justicialismo; el Partido Comunista; la Unión Cívica Radical; el Movimiento de Integración y Desarrollo, entre otras fuerzas, coincidían en condenar explícitamente la interrupción institucional en Chile. En esta línea, la Universidad del Comahue expresaba su apoyo al gobierno depuesto bautizando su aula Magna con el nombre de "Salvador Allende" ${ }^{67}$ Predominó en el diario un discurso que manifestaba una profunda solidaridad ante la "ofensiva imperialista" contra el proceso de "liberación" iniciado por el pueblo chileno. Cabe destacar que las habituales crónicas sobre los festejos de la independencia transandina que el diario publicaba cada 18 de septiembre, se transformaron en esta ocasión en espacios de denuncia del golpe y de improvisados homenajes a la memoria del presidente Allende. Las ciudades norpatagónicas de Neuquén, Cipolletti, Roca, Villa Regina, Cinco Saltos, Viedma y Cutral Co fueron escenario de actos en los que las asociaciones chilenas y distintas organizaciones políticas vernáculas expresaron su adhesión al gobierno de la Unidad Popular y a la resistencia a la dictadura. Según el diario, en Catriel los asistentes mostraron su solidaridad coreando: "Hermanos chilenos no bajen la bandera que acá estamos dispuestos a cruzar la cordillera" ${ }^{68}$ Con el efecto de verdad que genera la palabra de los "testigos", potenciados en este caso por la cercanía al ser habitantes de la región, el Río Negro

\footnotetext{
${ }^{64}$ Cf. "Confusa situación en Chile", 14 de septiembre de 1973; "El Gral. Prats ingresó en territorio argentino", 16 de septiembre de 1973.

${ }^{65}$ Cf. "Chile: tratan de reducir los últimos focos de resistencia", 16 de septiembre de 1973.

${ }^{66}$ Cf. "Hay más de 5000 detenidos en Chile", 18 de septiembre de 1973; "La junta de gobierno estudia una nueva política económica", 20 de septiembre de 1973; "Chile: declararon ilegales a los partidos marxistas", 22 de septiembre de 1973; "Se realizaron nuevos fusilamientos", 23 de septiembre de 1973; "Denuncian que hubo entre 400 y 500 fusilamientos", "Falleció anoche Pablo Neruda", 24 de septiembre de 1973; "La junta militar declaró ilegal a la CUT de Chile", 27 de septiembre de 1973; "Más fusilamientos en Chile", 28 de septiembre de 1973.

${ }^{67}$ Cf. "Chile: repercusiones en la región", 14 de septiembre de 1973; "Repudió el golpe en Chile, ayer la cámara neuquina, Chile", 15 de septiembre de 1973; "Chile. Reprueban el golpe entidades de la zona, UNC: apoyo al pueblo de Chile en una asamblea", 16 de septiembre de 1973.

${ }^{68}$ Cf. "Suspenden las fiestas chilenas en V. Regina (sic)", 14 de septiembre de 1973; "Chile", 21 de septiembre de 1973; "La independencia de Chile, conmemoróse", 19 de septiembre de 1973; "Chile. Repudio al golpe de Estado hubo en Viedma”, 20 de septiembre de 1973.
} 
publicó el relato de dos "barilochenses" detenidos en Chile en el que daban cuenta de la existencia de "torturas", "campos de concentración", "fusilamientos sumarios" y "encarnizadas persecuciones". ${ }^{69}$ Es importante señalar que no se registraron noticias situadas en la región que refirieran a enfrentamientos por cuestiones políticas entre residentes chilenos, como si se desprendía en las noticias provenientes de la ciudad de Mendoza. Allí se habían producido tensas discusiones entre ciudadanos chilenos que se encontraban de paso por la ciudad y otros que festejaban el golpe de Estado, luego de haber emigrado tras el triunfo de Salvador Allende. ${ }^{70}$ Esta ausencia pudo deberse a la composición social de la migración trasandina en uno y otro espacio. Mientras que la región de Cuyo históricamente constituyó un lugar preferido por las clases medias y altas chilenas, la Norpatagonia, como se ha señalado al comienzo del artículo, se convirtió tempranamente en el principal destino para los trabajadores.

En el escenario nacional, las primeras declaraciones públicas de Juan Domingo Perón evidenciaron el cambio político que estaba produciéndose en la Argentina. En ellas, si bien condenaba explícitamente que "un gobierno elegido por el pueblo fuera derrocado por fuerzas militares", al momento de establecer sus causas también sindicaba como responsables a los "apurados de siempre" ${ }^{71}$ En una entrevista a la televisión francesa, que Río Negro reprodujo en sus páginas, el líder del justicialismo afirmaba que Salvador Allende no había sido un revolucionario pero que los "guerrilleros" lo "empujaron mucho y allí está el resultado". ${ }^{72}$ Las noticias publicadas por el diario configuraban así un Perón menos preocupado por la repercusión que el "cambio de situación" chilena pudiera tener en la Argentina, que en convertir esa experiencia política en un ejemplo aleccionador sobre las consecuencias negativas de la "infiltración marxista" dentro de los gobiernos populares ${ }^{73}$ Esta identidad política, puesta en una cadena de equivalencias junto con la de "extremista", "subversivo" y "terrorista", volvía a convertirse en una representación estigmatizante (Franco, 2012).

En este nuevo contexto, fue conformándose progresivamente una zona del discurso en el que convergieron la dictadura chilena y el gobierno argentino, pero ya no sobre la base de la "liberación nacional" y la "justicia social" sino sobre la idea de que el marxismo era el antagonista en común. ${ }^{74}$

\footnotetext{
${ }^{69}$ Cf. "Relatos de testigos del golpe militar en Chile", 28 de septiembre de 1973.

${ }^{70} \mathrm{Cf}$. "El pueblo chileno soporta escasez de alimentos", 17 de septiembre de 1973.

${ }^{71}$ Cf. "Perón condenó el golpe militar en Chile. Manifestó que constituye una fatalidad para el continente", 13 de septiembre de 1973.

72 Cf. "Declaración de Perón para la TV francesa”, 21 de octubre de 1973.

${ }^{73}$ Cf. "Reportaje a Perón desde Madrid”, 12 de octubre de 1973.

${ }^{74}$ Cf. "La 'lucha frontal contra el marxismo' declaró Perón”, 30 de septiembre de 1973; "Severas directivas a gobernadores para la lucha contra el marxismo", 3 de octubre de 1973; "A combatir la infiltración en la esfera gremial", 3 de octubre de 1973; "Perón afirmó que la guerrilla está dirigida desde el exterior", 4 de octubre de 1973; "Pinochet acusó al marxismo de haber querido desatar una guerra en Chile", 12 de octubre de 1973; "La ilegalidad de los partidos marxistas y promarxistas en Chile", 25 de octubre de 1973; "La junta chilena advirtió que actuará violentamente contra los marxistas", 28 de octubre de 1973.
} 


\section{Reflexiones finales}

A modo de conclusión podemos afirmar que entre 1970 y 1973, el Río Negro, en tanto diario de frontera, desplegó en sus páginas un discurso sobre las relaciones binacionales en el que se alternaron como claves explicativas la influencia del contexto latinoamericano de la década de los sesenta y setenta, el posicionamiento del diario frente a la política nacional y provincial, y, finalmente, los estrechos vínculos que históricamente unieron a Chile con la Norpatagonia. En estas actuaciones públicas del diario se conjugaron la concepción del mundo sostenida por este medio, con los intereses políticos y económicos de esta empresa periodística presente en la región desde 1912.

En este sentido, a pesar de que las primeras noticias publicadas sobre el triunfo de la Unidad Popular dieron cuenta de las tensiones políticas generadas a uno y otro lado de la cordillera, el diario manifestó tempranamente, no sin cautela, sus expectativas sobre la posibilidad de que la "vía chilena al socialismo" pudiera convertirse en un antídoto contra los caminos revolucionarios que se referenciaban en la experiencia cubana. Desde esta perspectiva, instaba a la dictadura argentina a convocar a elecciones libres, sin proscripciones, en momentos en que la lucha armada adquiría mayor protagonismo en la vida política argentina. Esta demanda del diario también puede explicarse por la tensa relación que mantuvo el Río Negro con el último interventor militar, el cual avivó históricas disputas regionales dentro de la joven provincia.

Por otra parte, el cambio en las condiciones de producción y circulación de los discursos evidenciado hacia fines de 1969 generó desplazamientos de sentido que permitieron al diario volver a situar a la integración como el "imperativo histórico" al que debían subordinarse tanto los diferendos limítrofes como las disputas ideológicas. En este contexto, el acercamiento entre la dictadura de Alejandro Agustín Lanusse y el gobierno de Salvador Allende tuvo en el Río Negro a un entusiasta promotor, manifestando su interés tanto en las derivaciones políticas y económicas que traería a nivel nacional como en la forma que estos cambios incidirían en el espacio patagónico. La trascendencia que el diario asignaba a estos vínculos quedó de manifiesto en la dispar cobertura informativa sobre el viaje de Lanusse por Perú y Chile. Mientras que en el primer caso solo publicó algunas notas referidas a aspectos protocolares y a análisis de la reunión en clave de política doméstica; las noticias sobre el viaje a Antofagasta incorporaron también la relación personal entre los mandatarios, los acuerdos firmados y su impacto en la región, junto con diversos análisis que daban cuenta de las ventajas de profundizar los vínculos con Chile.

Sin embargo, a partir del incidente generado por la fuga del penal de Rawson y los posteriores fusilamientos de Trelew, la pertenencia ideológica de los gobiernos comenzó a configurar una dimensión determinante en el diario para comprender el rumbo que empezaban a tomar las relaciones entre ambos países. En las páginas de Río Negro se plasmó con claridad este nuevo escenario, tanto en los momentos de tensión generados por la negativa del gobierno de Allende a entregar "presos políticos" a la dictadura de argentina, como en aquellos en que la integración con Chile parecía adquirir una fisonomía más "nacional y antiimperialista". En los dos casos las noticias estuvieron centradas en la figura del presidente trasandino, en el primero atribuyéndoles la responsabilidad de incumplir con los acuerdos internacionales; mientras que en el segundo, destacando su protagonismo y popularidad en el escenario político nacional. A pesar de esta aparente contradicción, en ambos casos las noticias acabaron privilegiando el acercamiento con 
Chile, exaltando la figura presidencial cuando este parecía condensar cierto espíritu de unidad entre los pueblos y denostándola en momentos que la línea editorial del diario requería habilitar un desdoblamiento que permitiera concentrar en Allende las responsabilidades sobre las tensiones diplomáticas, diferenciándolo así del tradicional respeto a los acuerdos construidos como característica histórica e inalterables de los vínculos binacionales.

Finalmente, en el contexto del quiebre institucional que acabó con el camino al socialismo impulsado por la Unidad Popular, las páginas del Río Negro evidenciaron un claro predominio de voces que se alzaron para condenar el golpe, tanto en el plano nacional como regional. En este último, no solo emergieron como actores las distintas organizaciones que nucleaban a la comunidad de migrantes chilenos, sino también diversas instituciones norpatagónicas, entre las que se destacaron gobernadores, legislaturas provinciales, partidos políticos, centrales sindicales y universidades. Este unánime rechazo a la dictadura trasandina del que daba cuenta el diario, se reforzaba en sus editoriales, en los que advertía sobre la espiral de violencia que avizoraba para América Latina al obturarle a la izquierda la posibilidad de implementar cambios por la vía institucional.

Para finalizar, queríamos destacar el aporte de este tipo de estudios, los cuales permiten observar la polisemia desplegada en los medios en torno a conceptos como "frontera", "integración" y "migración", entre otros que fueron adquiriendo distintos sentidos en función de los entramados discursivos en los que se inscribieron. Esto adquiere mayor relevancia aún en el caso de la Norpatagonia, al tratarse de una región en la que los vínculos con Chile no configuran una referencia lejana y abstracta, sino que por el contrario, son un rasgo constitutivo de su historia.

\section{Referencias}

Altamirano, C. (2007). Bajo el signo de las masas (1943-1973). Buenos Aires, Argentina: Emecé.

Amossy, R. y Herschberg, A. (2001). Estereotipos y clichés. Buenos Aires, Argentina: Eudeba.

Ansaldi, W. (2004). Matriuskas de terror. Algunos elementos para analizar la dictadura argentina dentro de las dictaduras del Cono Sur. En A. R. Pucciarelli (Coord.), Empresarios, tecnócratas y militares. La trama corporativa de la última dictadura (pp. 27-51). Buenos Aires, Argentina: Siglo Veintiuno Editores.

Azcoitia, A. (2014). La fuga del penal de Rawson y los fusilamientos de Trelew según el diario Río Negro: tensiones políticas y operaciones discursivas. Historia Caribe, 9(25), 181-213.

Azcoitia, A. (2016). Las representaciones sobre las relaciones argentino-chilenas en la prensa norpatagónica. Un análisis del diario Río Negro (1960-1984) (Tesis doctoral inédita). Universidad Nacional del Sur, Argentina.

Bohoslavsky, E. (2009). El complot patagónico. Nación, conspiracionismo y violencia en el sur de Argentina y Chile (siglos XIX y Xx). Buenos Aires, Argentina: Prometeo.

Borrat, H. (1989). El periódico, actor político. Barcelona, España: Gustavo Gili. 
Cisneros, A. y Escudé, C. (2000). Historia general de las Relaciones Exteriores de la República Argentina (1806-1989). Buenos Aires, Argentina. Recuperado de http://www. argentina-rree.com./home_nueva.htm

Franco, M. (2012). Un enemigo para la Nación. Buenos Aires, Argentina: Fondo de Cultura Económica.

Gilman, C. (2003). Entre la pluma y el fusil. Debates y dilemas del escritor revolucionario en América Latina. Buenos Aires, Argentina: Siglo XXI.

Lacoste, P. (2003). La imagen del otro en las relaciones de la Argentina y Chile (1534-2000). Buenos Aires, Argentina: Fondo de Cultura Económica.

Martín, L. (1997). El orden social de los discursos. Discurso, 21(22), 1-37.

Mases, E., Rafart, G., Lvovich, D. y Quintar, J. (1998). El mundo del trabajo en Neuquén 1930-1970. Neuquén, Argentina: Educo.

Mazzei, D. (2012). Bajo El Poder de la Caballería. Buenos Aires, Argentina: Eudeba.

Medina, C. (2002). Chile y la integración latinoamericana: política exterior, acción diplomática y opinión pública, 1960-1976 (Tesis doctoral). Universidad Complutense de Madrid, España.

Medina, C. (2004). Chile y la integración latinoamericana: política exterior, acción diplomática y opinión pública, 1960-1976 (Tesis doctoral). Universidad Complutense de Madrid, España.

Mires, F. (1989). La rebelión permanente. Las revoluciones sociales en América Latina. México: Siglo XXI.

Moulián, T. (2006). Fracturas de Pedro Aguirre Cerda a Salvador Allende (1938-1973). Santiago, Chile: Lom Ediciones.

Nahmías, G. J. (2013). La batalla peronista. De la unidad imposible a la violencia política (Argentina 1969-1973). Buenos Aires, Argentina: Edhasa.

Pozzi P. y Schneider, A. (2000). Los setentistas: izquierda y clase obrera: 1968-1976. Buenos Aires, Argentina: Eudeba.

Raiter, A. y Zullo, J. (2008). La Caja de Pandora. Representaciones del mundo en los medios. Buenos Aires, Argentina: La Crujía.

Rapoport, M. (2005). Historia económica, política y social de la Argentina (1880-2003). Buenos Aires, Argentina: Ariel.

Riz, L. de (1981). Retorno y derrumbe. El último gobierno peronista. Buenos Aires, Argentina: Folios Ediciones.

Rodrigo, M. (2005). La construcción de la noticia. Barcelona, España: Paidós Comunicaciones.

Ruffini, M. (2001). Autoridad, legitimidad y representaciones políticas. Juegos y estrategias de una empresa perdurable: Río Negro y La Nueva Era (1904-1930). En L. Prislei (Dir.), Pasiones sureñas. Prensa, cultura y política en la frontera norpatagónica (1884-1946) (pp. 101-126). Buenos Aires, Argentina: Entrepasados, Prometeo libros.

Sigal, S. (1991). Intelectuales y poder en la década del sesenta. Buenos Aires, Argentina: Puntosur.

Sigal, S. y Verón, E. (2008). Perón o Muerte. Los fundamentos discursivos del fenómeno peronista. Buenos Aires, Argentina: Eudeba.

Simonoff, A. (2007). ¿Autonomía limitada o los límites de la autonomía? El análisis de la política exterior argentina durante la gestión de Illia (1963-1966) (Tesis doctoral). Universidad Nacional de la Plata, Argentina. 
Tapia, M. (2012). El Cipoletazo, una pueblada en el Alto Valle de Río Negro. Recortes políticos en los tiempos de la Revolución Argentina. En F. Camino (Coord.), El mundo de la política en la Patagonia Norte (pp. 111-145). Neuquén, Argentina: Educo.

Valdivia, V. (2010). 'EEstamos en guerra, señor!'. El Régimen Militar de Pinochet y el 'Pueblo', 1973- 1980. Historia, 1(43), 163-201.

Valenzuela, M. (1999). El enigma de la Laguna del Desierto. Una memoria diplomática. Santiago, Chile: LOM Ediciones.

Wodak, R. y Meyer, M. (2003). Método del análisis crítico del discurso. Barcelona, España: Gedisa.

Yappert, S. y Bohoslavsky, E. (2012). Liderazgo local, consignas nacionales y estrategias universales: el Rocazo de 1972. En F. Camino (Comp.) El mundo de la política en la Patagonia Norte (pp.147-172). Neuquén, Argentina: Educo.

Zapata, V. y Zurita, M. D. (2005). Las vacilaciones de la Revolución Argentina en su Política Exterior: ¿Alineamiento norteamericano o nacionalismo heterodoxo? Relaciones Internacionales, 14(29), 145-151.

Alfredo Azcoitia

Argentino. Profesor y doctor en Historia por la Universidad del Sur. Profesor de Historia Económica y Social General en la Universidad Nacional de Río Negro, en San Carlos de Bariloche, Argentina. Línea de investigación: el análisis de la prensa y las relaciones argentino-chilenas en el espacio patagónico. Publicación más reciente: "Del destino común a la invasión de... fuerzas armadas extranjeras en solo unas horas. Chile en la prensa norpatagónica durante el incidente de Laguna del Desierto". En M. A. Nicoletti, A. Núñez y P. Núñez (Comps.), Araucanía Norpatagonia. Discursos y representación de la materialidad (2016). 